\title{
Research on Service Quality Evaluation of Social Insurance Handling Based on SERVQUAL Model
}

\author{
Ming ZHOU ${ }^{a}$, Yu-Juan SHI ${ }^{b^{*}}$ \\ Full address of author, Northwest University, Xi'an, China \\ aemail1161592016qq.com, bemail2240544940@qq.com
}

\begin{abstract}
Keywords: SERVQUAL model, Index system of social insurance handling service quality, Service quality gap.
\end{abstract}

\begin{abstract}
The performance of social insurance management system reform is reflected by the participants' perception of the quality of social insurance services. In this paper, the "expectation perception" model in the field of service management is taken as the analysis framework, and a new social insurance handling service quality evaluation index system is set up. Through the questionnaire survey of the participants, the quality of the service of Zhengzhou after the implementation of the "five insurance one-in-one" model is made an empirical evaluation. The study find that the quality of service has been improved after the implementation of the "five insurance one-in-one" model, but there is still a gap with the public expected service level, especially in the aspects of humanized management, business capability and response capability. To further improve the service quality of the "five insurance one-in-one " model, we need to broaden the information sharing platform and channels, determine the service standards, improve the service concept, and strengthen the humanized management.
\end{abstract}

\section{Introduction}

As the executive department of the government, the social insurance handling management is an important institution for providing public service. How to provide the public with high efficiency and high-level service has always been the main goal of its reform, which is not only related to the improvement of the social security system, but also an important indicator of the level of the social security enterprise. The main work of service provided by the social insurance handling is to serve participants. The key to its quality of service is reflected by the public's satisfaction with the service process, while public satisfaction comes from the public's perception and expectation of service provided by the social insurance handling. With the social insurance reform and the continuous development of urban and rural co-ordination, the concept of public service has been improved, and the model of social insurance management is changing from "five insurances division" to "five-insurance-one-in-one", gradually become a trend. The study of the service quality of the social insurance handling service supply and the inner expectation of the insured person under the "five-insurance-one-in-one" model can not only find the shortcomings in the process of the social insurance agency service under this model, but also provide some reference for the reform of the social insurance handling management.

\section{Service Quality Index System}

\section{Related Research}

About service quality, Christian Gronroos thought it was the result and the difference between the customer's expectation of service and its actual experience, and proposed the customer perception service quality model, which laid the foundation for the study of service quality [1]. The SERVQUAL (Service Quality) model proposed by PZB, who divide service quality into five aspects: tangibility, reliability, responsiveness, assurance, and empathy, and used it to measure and evaluate the quality of service [2]. The SERVQUAL model is called the "service quality gap model", also known as the "expectation-perception" model. The core of the theory is that the high 
level of service quality depends on exceeding public expectations. Since the SERVQUAL model was introduced, it has been widely quoted in the service industry of domestic and foreign scholars. Because of the special features of the service, the scholar Cronin and Carman pointed out that it was not suitable for all service industries, and it needed to be amended when it was applied [3,4]. To make its service measurement more accurate, Getty pointed out that it must be adjusted to the actual situation to ensure the effectiveness of the scale [5]. Therefore, it is necessary to make appropriate adjustments to the indicators and dimensions of the SERVQUAL model, so that the evaluation results can be made more scientific and effective.

Most scholars have gone through the process of evaluating the quality of service in the public sector, which is guided by business standardization and standardization to public satisfaction. The public sector's service quality is also included in government performance evaluation [6]. The service quality of foreign social insurance public service agencies is mainly measured from two aspects of performance assessment and quality of service satisfaction evaluation. The former uses related methods of performance assessment to evaluate the performance of the department, and the latter uses the service object to evaluate the satisfaction of service quality by the scale evaluation [7]. For example, The Social Security Bureau of the United States adopts the dual evaluation method of target management and the American customer satisfaction index (CSI), the Central Liaison Office in Australia adopts the company management mode and introduces the management tool of the balanced scorecard. The domestic scholars' assessment of the quality of public sector services such as social security agencies is mainly to incorporate the satisfaction of the public into the performance evaluation index system and establish a set of Chinese customer satisfaction index model (CCSI) [8], which is applied to the research of social security agency service. Yan-Sui YANG has built the 4E model of performance evaluation of social security institutions, and evaluated the service from four aspects of economy, efficiency, benefits and fairness. The benefit is to evaluate the quality of service through the score of citizen satisfaction [9]. Shao-Guo ZHAI builds social insurance public service satisfaction evaluation index system for the participants, which is used to study the service quality of the agency under the "five insurances division" model [10]

With the continuous development of service management theory in business and the continuous advancement of service quality research in the public management field, the SERVQUAL evaluation model has gradually become a typical method for service management research to evaluate the quality of various public services [11]. Domestic scholars have widely applied it to public service quality research, mainly including medical and health services, pension services, public transportation, library services, and higher education and so on. Using the SERVQUAL evaluation model of service quality, the evaluation questions of the social insurance agency services can be objectively and reasonably quantified, which helps to understand the gap between the subjective expectations and the actual feelings of the public in the specific handling services. The direction and goals are of great significance to the reform and improvement of the social security management system.

\section{Evaluation Index System of Social Insurance Handling Service Quality}

In 1988, based on the Total Quality Management (TQM) theory, American marketing scientists A. Parasuraman, Zeithaml, and Berry, designed a comprehensive evaluation of five dimensions of service quality: a tangible facilities (Tangible); b Reliability; c Service efficiency (responsiveness); d guarantee (assurance); e emotional transference (empathy). Combining the five dimensions of the characteristics, functions, and service quality models of China's social insurance agency, establish a service quality index system that meets the requirements of the social insurance agency, as shown in the figure below. Through the establishment of an index system, a survey questionnaire is designed with this related issue, an objective evaluation of the service quality from the perspective of the participants', and then the service provider is helped to understand the "gap" between the participants' expectations and the participants' feelings in the specific service process, explore the reasons for the existence of the problems, so that the service can be improved clearly. 
Table1. The evaluation index system of social insurance handling service quality

\begin{tabular}{|c|c|}
\hline Dimensions & Index \\
\hline \multirow{4}{*}{$\begin{array}{l}\text { X1 } \\
\text { Environmental } \\
\text { facilities }\end{array}$} & Modern office equipment \\
\hline & Business handling environment is comfortable \\
\hline & Staff dress standard is neat \\
\hline & Public service facilities are used normally \\
\hline \multirow{5}{*}{$\begin{array}{l}\text { X2 } \\
\text { Business Capability }\end{array}$} & Policy advocacy is in place \\
\hline & Business staff solve your problems in a timely manner \\
\hline & Business staff can do one-time notification of existence \\
\hline & Staff business records can be checked \\
\hline & The staff can complete their business on time \\
\hline \multirow{4}{*}{$\begin{array}{l}\text { X3 } \\
\text { Response Capability }\end{array}$} & Business management has a fixed time \\
\hline & High efficiency of business process \\
\hline & Timely advice in the work of the staff \\
\hline & The staff can fully understand your needs \\
\hline \multirow{4}{*}{$\begin{array}{l}\text { X4 } \\
\text { Guarantee Capability }\end{array}$} & The staff's behavior makes you feel trusted \\
\hline & The business process makes you feel relieved \\
\hline & Staff remain polite \\
\hline & The staff is proficient in business \\
\hline \multirow{5}{*}{$\begin{array}{l}\text { X5 } \\
\text { Humanized } \\
\text { Management }\end{array}$} & The organization sets green channels and windows \\
\hline & $\begin{array}{l}\text { The agency provides differentiated services according to the } \\
\text { type of business }\end{array}$ \\
\hline & The agency helps you meet your special needs \\
\hline & The staff attaches great importance to what you care about \\
\hline & $\begin{array}{l}\text { The business handling time can be adjusted according to your } \\
\text { special circumstances }\end{array}$ \\
\hline
\end{tabular}

\section{Empirical Analysis of the Service Quality of Social Insurance Handing Organizations Data Collection}

Since 2013, Zhengzhou reform social insurance management system, by February 2017, in the whole city to realize the "1+15" service system, the implementation of the implementation of multiple types of horizontal integration of the "five risks one" of the big overall management of the new model. The five kinds of insurance, such as urban and rural pension, medical treatment, birth, industrial injury, and unemployment, are unified in one window and an office worker to realize the sharing of information. The data collection in this paper followed the principle of random sampling, and invited personnel who come to Zhengzhou City Bureau of Human Resources Protection to complete the questionnaire for the service quality of the organization. Respondents were asked to use a 5-point Li-kert scale to evaluate the expectations and perceptions of the indicators of service quality of the social insurance handing providing services. The meaning of 1-5 was unsatisfactory, dissatisfied, generally satisfied, more satisfied and satisfied. There were 130 respondents, of which 122 were valid questionnaires, and the effective rate was $93.8 \%$.

\section{The Reliability and Validity of the Questionnaire}

Table 2 Questionnaire reliability and validity test

\begin{tabular}{|c|c|c|c|c|}
\hline & & Sampling sufficier & Kaiser-Meyer-Olkin measure & 751. \\
\hline Cronbach 's Alpha & 826. & \multirow{3}{*}{$\begin{array}{l}\text { Bartlett spherical } \\
\text { test }\end{array}$} & The approximate chi-square & 670.591 \\
\hline $\begin{array}{l}\text { Cronbach Alpha based } \\
\text { on standardized terms. }\end{array}$ & 827. & & $\mathrm{df}$ & 231 \\
\hline Number & 22 & & Sig. & 000. \\
\hline
\end{tabular}

First, the paper uses SPSS19.0 [12] to calculate Cronbach's Alpha coefficient of the scale 0.826, which is higher than the critical value of 0.8 , which indicates that the reliability of the questionnaire is high, and has good internal consistency and strong credibility. Secondly, the validity of the contents of the questionnaire was tested. It is concluded that the value of KMO is 0.751 (more than 0.7), the sig value of Bartlett test is 0 , the significant level is less than 0.001 , and the approximate 
square value of the Bartlett spherical test is 670.591, that is, the correlation statistics between the data variables is significant. The questionnaire survey content is basically consistent with the actual needs, and the validity is higher. The results of the calculation are shown in the following table2:

\section{Service Quality Perception-Expectation Gap Analysis}

\section{Perception-Expectation Pairing Test}

Table 3 Perception-expectation pairing test

\begin{tabular}{|c|c|c|c|c|c|c|c|c|}
\hline & \multicolumn{8}{|c|}{ Difference in pairs } \\
\hline & \multirow[t]{2}{*}{ mean } & \multirow{2}{*}{$\begin{array}{l}\text { standard } \\
\text { deviation }\end{array}$} & \multirow{2}{*}{$\begin{array}{l}\text { standard } \\
\text { error of } \\
\text { mean. }\end{array}$} & \multicolumn{2}{|c|}{$\begin{array}{l}\text { 95\%confidence } \\
\text { interval for } \\
\text { difference. }\end{array}$} & \multirow[t]{2}{*}{$\mathrm{T}$} & \multirow{2}{*}{$\mathrm{f}$} & \multirow{2}{*}{$\begin{array}{l}\text { Sig. } \\
\text { (bilateral) }\end{array}$} \\
\hline & & & & $\begin{array}{l}\text { lower } \\
\text { limit }\end{array}$ & $\begin{array}{l}\text { Upper } \\
\text { limit }\end{array}$ & & & \\
\hline $\begin{array}{l}\text { Perception - } \\
\text { Expectation }\end{array}$ & -.57526 & .35885 & .03249 & -.63958 & -.51094 & 17.706 & 21 & 000. \\
\hline
\end{tabular}

Before the service quality gap analysis, the average value of the public perceived expectation (P) and expectation (E) is first matched with the paired sample $\mathrm{T}$ test (Paired-sample $\mathrm{T}$ test, given a significant level $\mathrm{p}=0.05$, according to the assumed value (P-Value)) to verify whether further analysis can be made. According to the test results in Table3, from the perspective of the public survey data, $\mathrm{t}=-17.706, \mathrm{p}<0.05$, so there is a significant difference between expectation and perception, and the gap between expectation and perception can be analyzed.

\section{Expectations - Perceived Gap Analysis}

Table 4 Expected-Perceived gap analysis for each dimension

\begin{tabular}{|c|c|c|c|c|c|c|c|c|}
\hline \multirow{2}{*}{ Dimension } & \multirow{2}{*}{ Indicators } & \multicolumn{4}{|c|}{ Mean } & \multirow{2}{*}{\multicolumn{2}{|c|}{ SQ }} & \multirow{2}{*}{ Significant } \\
\hline & & & ption & & & & & \\
\hline \multirow{4}{*}{ X1 } & $\mathrm{x} 1$ & 3.98 & \multirow{4}{*}{4.02} & 4.48 & \multirow{4}{*}{4.43} & -0.50 & \multirow{4}{*}{-0.41} & \multirow{22}{*}{$0.00 *$} \\
\hline & $\mathrm{x} 2$ & 3.90 & & 4.38 & & -0.48 & & \\
\hline & x3 & 4.31 & & 4.44 & & -0.13 & & \\
\hline & $\mathrm{x} 4$ & 3.90 & & 4.43 & & -0.53 & & \\
\hline \multirow{5}{*}{ X2 } & x5 & 3.78 & \multirow{5}{*}{3.80} & 4.41 & \multirow{5}{*}{4.40} & -0.63 & \multirow{5}{*}{-0.60} & \\
\hline & x6 & 3.68 & & 4.32 & & -0.64 & & \\
\hline & X7 & 3.57 & & 4.31 & & -0.74 & & \\
\hline & $\mathrm{x} 8$ & 3.79 & & 4.34 & & -0.55 & & \\
\hline & x9 & 4.19 & & 4.63 & & -0.44 & & \\
\hline \multirow{4}{*}{ X3 } & $\mathrm{x} 10$ & 4.43 & \multirow{4}{*}{3.93} & 4.59 & \multirow{4}{*}{4.48} & -0.16 & \multirow{4}{*}{-0.55} & \\
\hline & x11 & 3.80 & & 4.44 & & -0.64 & & \\
\hline & $\mathrm{x} 12$ & 3.80 & & 4.48 & & -0.68 & & \\
\hline & $\mathrm{x} 13$ & 3.71 & & 4.41 & & -0.70 & & \\
\hline \multirow{4}{*}{ X4 } & $\mathrm{x} 14$ & 4.02 & \multirow{4}{*}{4.00} & 4.30 & \multirow{4}{*}{4.41} & -0.28 & \multirow{4}{*}{-0.41} & \\
\hline & x15 & 4.20 & & 4.48 & & -0.28 & & \\
\hline & $\mathrm{x} 16$ & 3.72 & & 4.37 & & -0.65 & & \\
\hline & x17 & 4.07 & & 4.49 & & -0.42 & & \\
\hline \multirow{5}{*}{ X5 } & x18 & 3.26 & \multirow{5}{*}{3.41} & 4.20 & \multirow{5}{*}{4.25} & -0.94 & \multirow{5}{*}{-0.84} & \\
\hline & $\mathrm{x} 19$ & 3.71 & & 4.36 & & -0.65 & & \\
\hline & $\mathrm{x} 20$ & 3.73 & & 4.35 & & -0.62 & & \\
\hline & x21 & 3.20 & & 4.11 & & -0.91 & & \\
\hline & $\mathrm{x} 22$ & 3.12 & & 4.17 & & -1.05 & & \\
\hline
\end{tabular}

Note $* 95 \%$ confidence was significantly correlated $(\mathrm{p}<0.05)$

The data shows that the perspective of the public under the five dimensions is that the expected average value of the indicators of service quality of social insurance agency in Zhengzhou City, which is larger than that of perception, and the overall gap between the guarantee capacity and the environment and facilities is the same, while the five dimensions of operational capacity, responsiveness and humane management The gap is gradually widening, and the perceived gap in 
service quality in each dimension is $-0.41,-0.41,-0.55,-0.60$, and -0.84 , respectively. In the service industry of China, the service quality score 4 is divided into medium level, which indicates that to a certain extent, the social insurance agency in Zhengzhou has reached an intermediate level in terms of environmental management, facilities, and support capabilities, but still has ability to respond and service. It needs to be further improved. In particularly, the perception and expectations of humanistic management are bottoming out and need to be improved. The analysis of each dimension index is shown Table 4:

Environmental facilities in Table 4, Staff dress standard is neat, business handling environment is comfortable, modern office equipment and public service facilities are used normally, and the perceived gap is gradually increasing. They are $-0.13,-0.48,-0.50$, and -0.53 , respectively. The agency has made clear requirements on the staff's dress, has reached a higher level, the public perception of the gap between the smaller expectations, in addition to the handing service hall set up a considerable number of waiting seats, handling and waiting for a better environment.

Business capability in Table 4, the perception-expectation gap scores are ranked so that the staff can complete their business on time, staff business records can be checked, policy advocacy is in place, business staff solves your problems in a timely manner, and business staff can do one-time notification of existence. The questions are $-0.44,-0.55,-0.63,-0.64,-0.74$, respectively. As a government agency, the business personnel of the social insurance agency do a better job in completing business management and business records on time and meet the requirements of high efficiency and high quality that the country advocates. Therefore, these two gaps are relatively small. Business personnel can make one-time notification that there is a problem gap that is the lowest one in the score. In the process of service, the organization staff often ends up the service after negating a material, at the time, if the business management personnel are there are also problems with the materials, which will lead to an increase in the number of round-trips, and the satisfaction of personnel handling the business will be greatly reduced.

Response capability in Table 4, in the sense of perceived expectation gap, business management has a fixed time, high efficiency of business process, and timely advice in the work of the staff, and the staff can fully understand your needs, gradually widening respectively, $-0.16,-0.64,-0.68,-0.70$. This shows that there are major problems in the efficiency, response efficiency and attitudes of the social security office staff of the agency. The low speed and attitude of the office is the main reason why the appraisers have low evaluation of the responsiveness of the agency. In this regard, relevant agencies should take measures to improve as soon as possible.

Guarantee capability in Table 4, the business process makes you feel relieved, the staff's behavior makes you feel trusted, the staff is proficient in business, and the staff remain polite, the gap is increasing respectively, $-0.28,-0.28,-0.42,-0.65$. The gap is greater courtesy, followed by business proficiency, and the gap is less trust and security. As a staff member at the window, people who receive the same business repeatedly on daily basis are, from a psychological point of view, inevitably unavoidable. The staff's business proficiency gap score is greater than -0.5 , indicating that the business proficiency of the business staff needs to be further improved. As part of government agencies, the respondents expressed greater recognition of their trust and security.

Humanized management in Table 4, from the above data analysis, humanized management is the lowest SQ value among the five dimensions. The average difference is -0.84 . In its dimension, the agency helps you meet your special needs, the agency provides differentiated services according to the type of business, the staff attaches great importance to what you care about, the organization sets green channels and windows, and the business handling time can be adjusted according to your special circumstances has gradually increased. They are $-0.62,-0.65,-0.91,-0.94$, and -1.05 , which are generally larger than the indicators in the above dimensions. This shows that the agency needs to focus on improvement carrying out this dimension. In addition, in the actual business process, the elderly and young people often piled up in front of the window and wait for the number to handle the business. Although this guarantees fairness to a certain extent, it needs to be improved from the perspective of a people-centered approach, and related institutions can explore how to proceed. The window is divided to increase the score of the item. 


\section{Conclusions and Recommendations}

From the above analysis, it can be known that the quality of service experienced by the participants in the actual acceptance of services is generally lower than that expected by service personnel, and the overall service quality of the social insurance handing cannot be brought after the reform of the management and operation model. The public handling the business is dissatisfied. Among these, humane management is the most dissatisfied, and it is unsatisfied in terms of business capability and response capability, yet it is relatively unsatisfactory in terms of environment, facilities, and guarantee capability. Meanwhile, it could find that the specific problems were mainly due to the inadequacy of information construction behind demand, lack of institutional propaganda, ambiguous staff responsibilities, resulting in relatively low efficiency of service, lack of staff service concepts, and specially lack of humane management and services for special group awareness. Through investigation, it was learned that the agency's unclear understanding of the needs of the public led to a deviation between the focus of service provision and public expectations. Among the five dimensions, respondents had the highest expectation of responding ability, but the perception of the higher office staff was the environment for institution building. In addition, with facilities and support capabilities, the lack of publicity of the organization and the lack of external communication make it possible for the public to reach out to the handling agency when they first handle the social security business. They have less knowledge of many policies and business contents and obtain a poor service experience. Especially in the service process, excessive emphasis has been placed on institutionalized management and lack of humanistic care. The relevant agencies of the Social Security Administration do not consider the convenience needs of certain special groups to maintain fairness and institutional standards. Therefore, to further improve the service quality of the agency under the "five-insurance-one-in-one" model, the following points need to be achieved:

Expand the information platform and broaden the external communication channels. With the development of social security in Zhengzhou City, the population covered by social insurance continues to expand, and the services of participating units and individuals involved need to be diversified and individualized. The Social Security Agency should establish a social security management platform to build both the two channels of external communication and the supervisory evaluation function. Using advanced technology, publicly and widely disseminate information to the public, so that the public can feel that the social security system is serving the people in fact and promote their own public service level.

Based on public demand, service standards are formulated. Standardizing service time, business, service attitudes, and service procedures make it important for the staff's service to influence the quality of service. It can allow business managers to feel professional and assured. However, due to the limited energy of the staff, at the same time, it is difficult to take in account multiple standards. At the time, we should proceed from the needs of the public and rationally divide the primary and secondary relationship. Standard formulation should be close to the needs of the public and effectively provide the public with a high level of services.

Improve service concept and strengthen service awareness. At present, the evaluation of the hardware facilities of the social security agency is relatively high, but the management concept and service awareness are relatively backward, and the gap between Participants expectation perception is mainly reflected in the service consciousness. As a service-oriented window, the social security agency should optimize the service concept. The staff must have systematic training and learning of service skills before starting the job, and enhance service awareness. It promotes the establishment of a service satisfaction performance appraisal and encourages staff to provide better services.

Strengthen humane management and promote special care needs. Firstly, we should further improve the green channel, which can handle some social security-related fast-track channels for special people. This is a manifestation of the humanistic care and humane management of the handling agencies. It is not only convenient for special people's business processes, but also an important way to create a harmonious society atmosphere. Secondly, as a responsible state agency, the social insurance agency should also pay attention to the physical and mental health of the 
special population and give them adequate humanistic care and assistance. In addition, the humane management requirements for the agency are not only reflected in the service quality of the special population, but also reflected in the special needs of the people handling some businesses. If some of the materials are lost and cannot be recovered, the handling agency should also address its special reality. The situation provides them with differentiated solutions to help them handle the social security business and improve the service quality of the agency from a special perspective.

\section{Acknowledgement}

This research was financially supported by The National Social Science Fund Project "Social Insurance Unified Handling Mode and Implementation Path" (13BGL117) stage results.

\section{References}

[1] Christian Gronroos, A Service Quality Model and its Marketing, Marketing placation [J] European Journal of marketing (1984) 18(4):36-44.

[2] A. Parasuraman, Zeithaml, Berry, A Multiple-item scale for measuring consumer perception scale for measuring consumer perceptions of service quality [J]Journal Retailing (1988) pp.12-40.

[3] Cronin, Measuring Service Quality: Reexamination and Extension [J]Journal of Marketing (1992).56(3) pp.55-68.

[4] Carman, Consumer. Perceptions of Service Quality: An Assessment of the SERVQUAL Dimensions [J] Journal of Retailing (1990) pp.33-55.

[5] Getty, Lodging quality index (LQI): assessing customer perceptions of quality delivery [J] International Journal of Contemporary Hospitality Management, (2003) 02.94-104.

[6] Hong-Min SHI, On the Quality Assessment Model of Public Service [J]Journal of the Party School of CPC Zhengzhou Municipal Committee (2004).02.

[7] Zhi-Ren SHI, Performance Evaluation of Public Organizations: The Practice of Britain and Its Enlightenment to US [J] New vision (1995) 05.

[8] Wu LIU, Measurement of Customer Satisfaction in Government Public Service [J]Journal of Northeastern University (Social Science), (2006) pp.129-132.

[9] Yan-Sui YANG, Research report on the construction of performance evaluation system for social insurance agencies, Research report on capacity building of social insurance agencies, (2008).10.

[10] Shao-Guo ZHAI, The Evaluation of Social Insurance Public Service Satisfaction-Taking Taiyuan as an Example [J]Journal of HE BEI University (Philosophy and Social Sciences), 2017(03).

[11] Lin-Hua LOU, Research on SERVQUAL Service Quality Evaluation Model [J]Technology and Market (2015).01.

[12] Yan-Li. JIA, <SPSS statistical analysis>[M]Beijing: People's Posts and Telecommunications Press (2011) pp.248-320. 